\title{
Facial Divine Proportions in Attractive North Indian Females: A Photographic Study
}

\author{
Anand Awadhesh Tripathi, Ragni Pradip Tandon, Navin Hantodkar
}

\begin{abstract}
Purpose: The purpose of the study is to find the divine proportion in young attractive North Indian women.
\end{abstract}

Materials and methods: Thirty young unmarried women perceived to be attractive out of 100 subjects (18-26 years age group) representing North Indian population were selected by a panel of judges from different background. Divine proportions were evaluated in these women by using Ricketts RM (1982) Divine Proportion Analysis on frontal facial photographs.

Results and observations: The subjects in the group adhered to the golden proportions. The ' $t$ ' test was significant $(t \leq 2.05)$ for facial height and width ratios.

Conclusion: Ratios in transverse and vertical dimension as well as soft tissue of attractive face affirm to the divine proportion.

Keywords: Divine proportion, Attractive face, Facial width, Facial height.

How to cite this article: Tripathi AA, Tandon RP, Hantodkar N. Facial Divine Proportions in Attractive North Indian Females: A Photographic Study. World J Dent 2013;4(1):41-46.

Source of support: Nil

Conflict of interest: None declared

\section{INTRODUCTION}

Leonardo Da Vinci pointed out the affinity between proportion and harmony when he talked of 'proportional beauties of an angelic face'.

Beauty or facial attractiveness of an individual has almost always been a feature which causes a favorable reaction in social interaction. Facial harmony and balance are determined by facial skeleton and its soft tissue drape. In facial system, no such background information was known until the beginning of anthropometries. Physical appearance particularly where others find it pleasing or displeasing dramatically effects the behavior pattern in life. ${ }^{1}$ The development of esthetic awareness begins early in childhood with the instinct 'What is beautiful; is good!'

Harmony in a face expresses the morphologic perfection connected with an unquestionable charm. The concrete basis for identification of normality is established through the factor that causes the feeling of harmony-'Proportion'. Facial harmony in orthodontics is determined by the morphologic relationships and proportion of nose, lips and chin. Because the balance between these anatomic structures can be altered by both growth and orthodontic treatment, it is essential for the orthodontist to understand his role in making facial beauty. ${ }^{3}$

Ricketts RM (1982) ${ }^{2}$ analyzed the proportion between various facial components and proposed the magical divine proportion (Kepler, 1600) ${ }^{3}$ of 'Phi $(\phi)$ ' i.e. 1:1.618, ${ }^{4}$ (Fig. 1) between the facial structures 'Phi' (Fig. 2) has been related to aspects of beauty and it has been a matter of curiosity for artists, mathematicians, scientists and philosophers.

There exists a relationship between Fibonacci series/ the divine proportion and the beautiful art in nature; like the intersecting spirals in sunflower or pine cones, the beautiful bands on the wings of a butterfly, the symmetrical veins of a tree leaf, the exhilarating color proportions of a peacock feather or the logarithmic spirals of a snails (Nautilus). ${ }^{5}$

The aim of this study is to evaluate the divine proportion in attractive North Indian females by means of measurements on photographs.

\section{MATERIALS}

The study was conducted in the Department of Orthodontics and Dentofacial Orthopedics, Saraswati Dental College and Hospital, Lucknow, Uttar Pradesh, India.

A group of 100 young unmarried females of 18 to 26 years of age group with reasonably pleasing faces comprise the initial sample for the study. All the subjects had a full complement of permanent teeth with no history of orthodontic treatment. The selected individuals were healthy and showed a good balance and harmony of dentofacial structures. Facial photographs of the 100 subjects were taken using Sony Cybershot DSC-T70 digital camera. Photographs (Fig. 3) were taken with subject in natural head posture. ${ }^{6-8}$ The photographs were standardized using Adobe PhotoShop CS4 software.

Facial photographs of the group were subjected to a selection process by a panel of judges ${ }^{9-14}$ comprising of orthodontist, oral and maxillofacial surgeon, prosthodontist, beautician and layman (all were having experience more than 30 years in their respective profession) with focus on the balance in facial parts, disregarding individual highlights (beautiful eyes, hairs, etc). ${ }^{15,16} \mathrm{~A}$ scoring sheet was made and given to individual judge. ${ }^{17}$ Points were given to individual subject out of 10 by the judge, then added and 


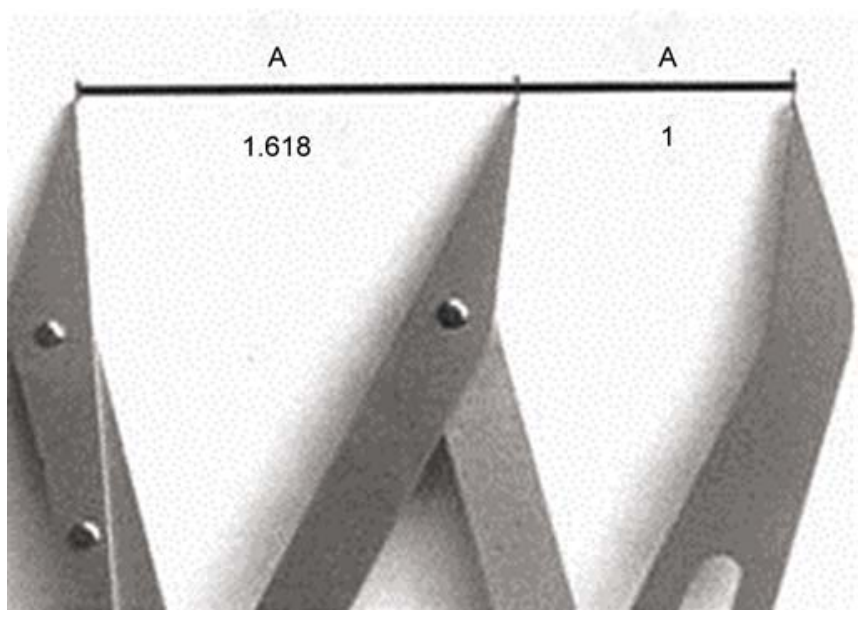

Fig. 1: Golden divider showing golden ratio

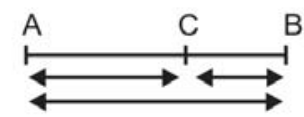

$C B: A C=A C: A B=1: 1.618$
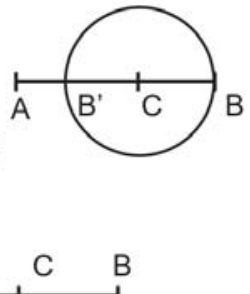

AB:C'B-1:1.618

Fig. 2: The golden ratio is divided

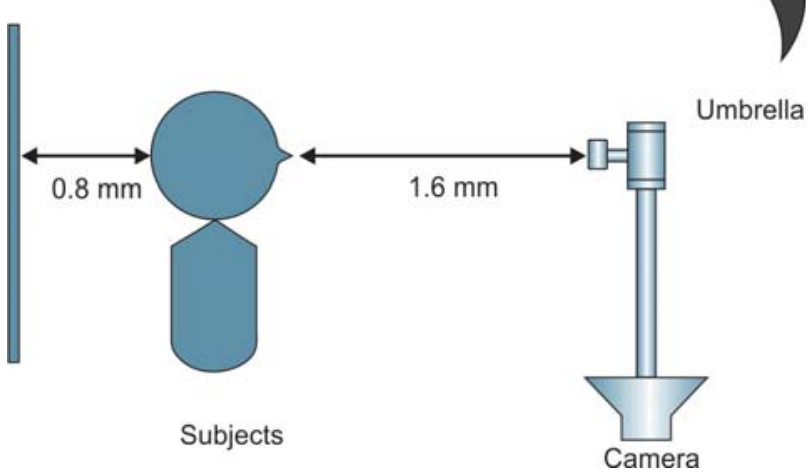

Fig. 3: Method of taking a frontal photo of subject

top 30 scorers were selected from the above group and formed the database for further photographic analysis.

\section{METHODS}

The facial photographs were measured and analyzed using digital Vernier caliper with nearest of $0.01 \mathrm{~mm}$ accuracy.

\section{Frontal Photographic Measurements and Analysis}

Transverse facial measurement landmarks are as follows:

1. LN-Lateral rim of ala of nose.
2. $\mathrm{CH}-$ Cheilion point at the angle of the mouth.

3. LC - Point at the lateral canthus of eye.

4. TS-Point at the lateral border of temple at the level of the eye.

Vertical facial measurement landmarks are as follows:

1. Trichion (TR): Point at beginning of hair on the forehead in young people, which corresponds to the point at the junction of facial and skull fascia.

2. Lateral canthus of eye (LC): A point situated on the midline of face corresponding to superior border of alar curve of the nose.

3. Alar curve of the nose $(A L)$ : Point situated on the midline of nose corresponding to the superior border of alar curve of nose.

4. Cheilion ( $\mathrm{CH})$ : Midpoint between the upper and lower lips selected at level of stomion.

5. Menton (M): Point corresponding with soft tissue menton at the lower border of soft tissue chin.

All possible intermeasurement ratios between the vertical and transverse landmarks of the face was evaluated for any statistically significant ratio equivalent to the golden proportion constant 1.618 (divine proportion).

\section{STATISTICAL TOOLS}

The statistical analysis was done using SPSS (statistical package for social sciences) version 15.0 statistical analysis software. The values were represented in number (\%) and mean $\pm \mathrm{SD}$.

The following statistical formulas were used:

1. Mean: To obtain the mean, the individual observations were first added together and then divided by the number of observation. The operation of adding together or summation is denoted by the sign $\Sigma$.

The individual observation is denoted by the sign $\mathrm{X}$, number of observation denoted by $\mathrm{n}$, and the mean by $\bar{X}$.

$$
\bar{X}=\frac{\sum X}{\text { No. of observations (n) }}
$$

2. Standard deviation: It is denoted by the Greek letter $\sigma$. If a sample is more than 30 then,

$$
\sigma=\sqrt{\frac{\sum(\mathrm{X}-\overline{\mathrm{X}})^{2}}{n}}
$$

When sample in less than 30 then,

$$
\sigma=\sqrt{\frac{\sum(X-\bar{X})^{2}}{n-1}}
$$


3. Coefficient of variance (\%)

$$
\mathrm{COV}=(\mathrm{SD} / \text { mean }) \times 100
$$

4. Standard error mean: $\mathrm{SEM}=\mathrm{SD} / \sqrt{\mathrm{n}}$ means that the standard deviation divided by square root of ' $n$ '. As number of sample increases SEM decrease, that is why it is preferred to have greater number of samples.

5. One-sample ' $t$ ' test

$$
\mathrm{t}=\frac{\overline{\mathrm{X}}-\mu}{\mathrm{S}} \sqrt{\mathrm{n}}
$$

Where,

$\mathrm{t}=$ One sample $\mathrm{t}$-test

$\mu=$ Population mean (in this case the divine ratio)

$\mathrm{S}=$ Standard deviation for one sample t-test

$\overline{\mathrm{X}}=$ Sample mean

$\mathrm{n}=$ Number of observations in sample

6. ' $t$ ' test critical value: For one sample ' $t$ ' test the critical value at $95 \%$ confidence level and degree of freedom 29 , was calculated to be 2.05 , any value above to this is significant.

As ' $t$ ' test exceeding the critical value, it was considered to be showing significant difference from group of population mean (golden proportion/divine ratio).

7. Level of significance: ' $t$ ' is level of significance

$\mathrm{t} \leq 2.05$ : Significant

$\mathrm{t} \leq 2.75$ : Highly significant

$\mathrm{t} \leq 3.65$ : Very highly significant

\section{RESULTS}

\section{Frontal Transverse Relation}

The ratio for analysis of golden proportion in transverse dimension were calculated by ratio between two transverse landmarks of linear measurements with other two transverse landmark of linear measurement viz TS-TS:LC-LC, LCLC:LC-LN-LN and so on (Fig. 4).

Mean of frontal width relation ratio with ' $t$ ' value for 30 samples are shown in Table 1 and Graph 1. The ' $t$ ' test

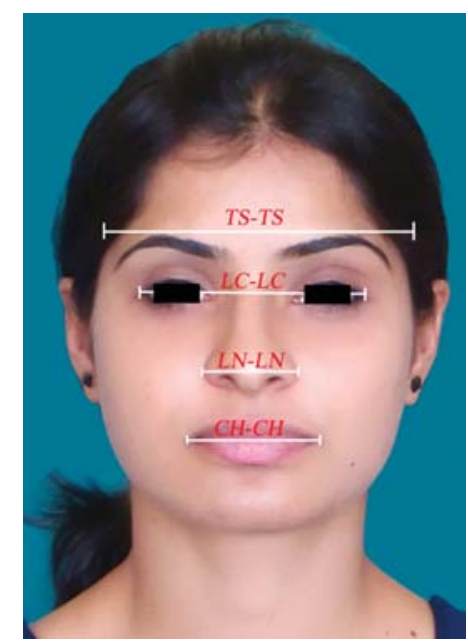

Fig. 4: Landmarks and measurements for facial width analysis

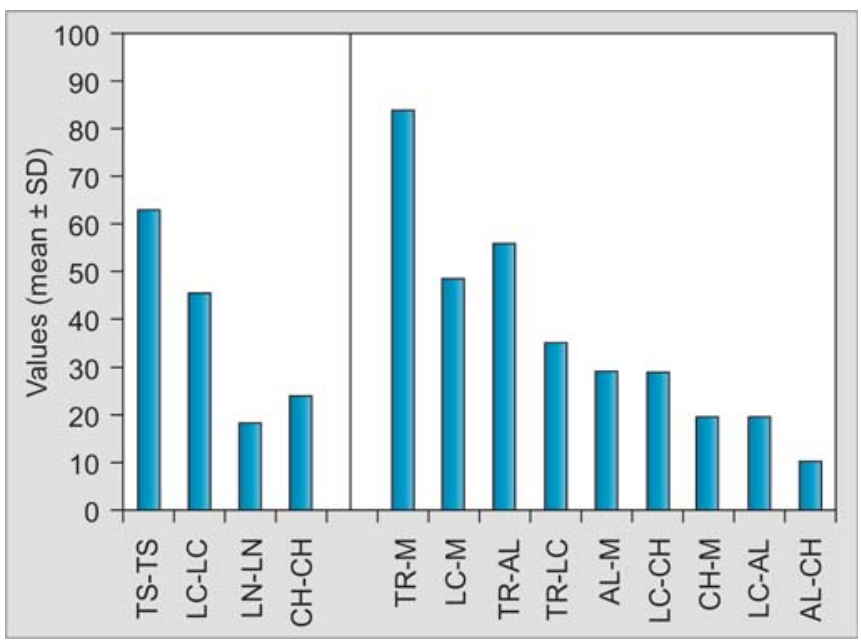

Graph 1: Photographic transverse and vertical measurements $(\mathrm{mm})$

critical value at $95 \%$ confidence level and degree of freedom 29 , was calculated to be 2.05 , any value above to this is significant. Table 2 shows the statistically very high significant ratios between transverse measurements as tested by ' $\mathrm{t}$ ' test at $\mathrm{t} \leq 3.65 \%$ (Table 2 and Graph 2 ).

\section{Frontal Vertical Relation}

The vertical analysis included nine vertical measurements

\begin{tabular}{|c|c|c|c|c|c|c|c|c|c|}
\hline & \multicolumn{8}{|c|}{ Transverse } & \\
\hline & TS-TS & & $L C-L C$ & & \multicolumn{3}{|c|}{$L N-L N$} & \multirow{2}{*}{\multicolumn{2}{|c|}{$\frac{\mathrm{CH}-\mathrm{CH}}{23.83}$}} \\
\hline Mean & 62.71 & & 45.51 & & \multicolumn{3}{|c|}{18.18} & & \\
\hline $\mathrm{SD}$ & 1.88 & & 1.98 & & \multicolumn{3}{|c|}{1.27} & \\
\hline COV (\%) & 3.00 & & 4.34 & & & 7.01 & & \multicolumn{2}{|r|}{5.66} \\
\hline \multicolumn{10}{|c|}{ Vertical } \\
\hline & TR-M & LC-M & TR-AL & TR-LC & AL-M & LC-CH & $\mathrm{CH}-\mathrm{M}$ & LC-AL & $\mathrm{AL}-\mathrm{CH}$ \\
\hline Mean & 83.90 & 48.27 & 55.80 & 35.04 & 28.86 & 28.77 & 19.27 & 19.28 & 10.01 \\
\hline $\mathrm{SD}$ & 3.89 & 2.253 & 5.30 & 3.03 & 2.08 & 1.25 & 1.37 & 1.27 & 0.87 \\
\hline COV (\%) & 4.64 & 4.67 & 9.50 & 8.65 & 7.21 & 4.35 & 7.11 & 6.61 & 8.69 \\
\hline
\end{tabular}
from frontal photograph (Fig. 5) as shown in Table 1 and 


\begin{tabular}{|c|c|c|c|}
\hline & Mean & $S D$ & Test for divine proportion \\
\hline \multicolumn{4}{|c|}{ Transverse } \\
\hline TS-TS/LC-LC & 2.25 & 0.25 & 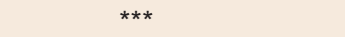 \\
\hline LC-LC/TS-TS & 0.45 & 0.05 & * \\
\hline TS-TS/LN-LN & 1.00 & 0.06 & * \\
\hline LN-LN/TS-TS & 1.00 & 0.06 & * \\
\hline TS-TS/CH-CH & 2.25 & 0.20 & $\star \star \star$ \\
\hline $\mathrm{CH}-\mathrm{CH} / \mathrm{TS}-\mathrm{TS}$ & 0.45 & 0.04 & * \\
\hline LC-LC/LN-LN & 0.45 & 0.04 & * \\
\hline LN-LN/LC-LC & 2.25 & 0.20 & $\star \star \star *$ \\
\hline $\mathrm{LC}-\mathrm{LC} / \mathrm{CH}-\mathrm{CH}$ & 1.00 & 0.06 & * \\
\hline $\mathrm{CH}-\mathrm{CH} / \mathrm{LC}-\mathrm{LC}$ & 1.00 & 0.06 & * \\
\hline LN-LN/CH-CH & 2.25 & 0.24 & $\star \star \star *$ \\
\hline $\mathrm{CH}-\mathrm{CH} / \mathrm{LN}-\mathrm{LN}$ & 0.45 & 0.05 & * \\
\hline \multicolumn{4}{|c|}{ Vertical } \\
\hline TR-M/LC-M & 1.74 & 0.07 & $\star \star$ \\
\hline LC-M/TR-M & 0.59 & 0.02 & $\star \star \star$ \\
\hline TR-M/TR-AL & 1.58 & 0.11 & $\star \star \star ~$ \\
\hline TR-AL/TR-M & 0.65 & 0.07 & * \\
\hline LC-M/TR-LC & 1.39 & 0.12 & * \\
\hline TR-LC/LC-M & 0.73 & 0.06 & * \\
\hline TR-AL/AL-M & 1.94 & 0.22 & * \\
\hline AL-M/TR-AL & 0.52 & 0.05 & * \\
\hline AL-M/LC-AL & 1.50 & 0.15 & * \\
\hline LC-AL/AL-M & 1.68 & 0.10 & $\star \star \star *$ \\
\hline $\mathrm{LC}-\mathrm{CH} / \mathrm{CH}-\mathrm{M}$ & 1.50 & 0.10 & $\star *$ \\
\hline $\mathrm{CH}-\mathrm{M} / \mathrm{LC}-\mathrm{CH}$ & 0.64 & 0.04 & $\star \star \star *$ \\
\hline $\mathrm{CH}-\mathrm{M} / \mathrm{AL}-\mathrm{CH}$ & 1.93 & 0.15 & * \\
\hline $\mathrm{AL}-\mathrm{CH} / \mathrm{CH}-\mathrm{M}$ & 0.52 & 0.04 & * \\
\hline LC-AL/AL-CH & 1.94 & 0.23 & * \\
\hline AL-CH/LC-AL & 0.52 & 0.06 & * \\
\hline LC-M/AL-M & 1.68 & 0.10 & * \\
\hline AL-M/LC-M & 0.60 & 0.03 & * \\
\hline LC-M/LC-CH & 1.68 & 0.05 & $\star \star \star ~$ \\
\hline LC-CH/LC-M & 0.60 & 0.02 & * \\
\hline TR-AL/TR-LC & 0.87 & 0.06 & * \\
\hline TR-LC/TR-AL & 1.16 & 0.10 & * \\
\hline TR-AL/LC-CH & 1.94 & 0.21 & * \\
\hline LC-CH/TR-AL & 0.52 & 0.04 & * \\
\hline TR-LC/CH-M & 1.82 & 0.15 & * \\
\hline $\mathrm{CH}-\mathrm{M} / \mathrm{TR}-\mathrm{LC}$ & 0.58 & 0.05 & $\star \star \star *$ \\
\hline TR-LC/LC-AL & 1.82 & 0.19 & * \\
\hline LC-AL/TR-LC & 0.59 & 0.06 & $\star \star \star *$ \\
\hline AL-M/CH-M & 1.50 & 0.08 & ** \\
\hline CH-M/AL-M & 0.67 & 0.04 & 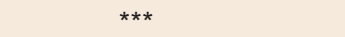 \\
\hline LC-CH/LC-AL & 1.50 & 0.08 & $\star \star *$ \\
\hline LC-AL/LC-CH & 0.67 & 0.04 & * \\
\hline
\end{tabular}

${ }^{*} p<0.05$ : Significant; ${ }^{* \star} p<0.01$ : Highly significant; ${ }^{* \star *} p<0.001$ : Very highly significant

Graph 1. Statistically significant ratios between vertical measurements as tested by ' $\mathrm{t}$ ' test at $\mathrm{t} \leq 2.05 \%$ are shown in Table 2 and Graph 2.

\section{DISCUSSION}

Results in this study on the facial width proportion (transverse) analysis showed with reference to ' $t$ ' test critical value (2.05) that TS-TS:LC-LC (width of the head at temporal soft tissue is golden to lateral width of eyes at the lateral canthus; 2.249), TS-TS:CH-CH (width of head at temporal soft tissue is golden to width of mouth; 2.249), LN-LN:LC-LC (width of nose is golden to lateral width of eyes at the lateral canthus), LN-LN:CH-CH (width of nose is golden to width of mouth; 2.252), where $t \leq 3.65$, was very highly significant.

In our study we found TS-TS:LC-LC (width of the head at temporal soft tissue is golden to lateral width of eyes at the lateral canthus) to be 2.249. This is similar to the results found by Mizumoto et $\mathrm{al}^{18}$ who did a photographic analysis on young Japanese women and found that the ratio TS-TS:LC-LC was 1.620.

We also found that TS-TS:CH-CH (width of head at temporal soft tissue is golden to width of mouth; 2.249), LN-LN:LC-LC (width of nose is golden to lateral width of 


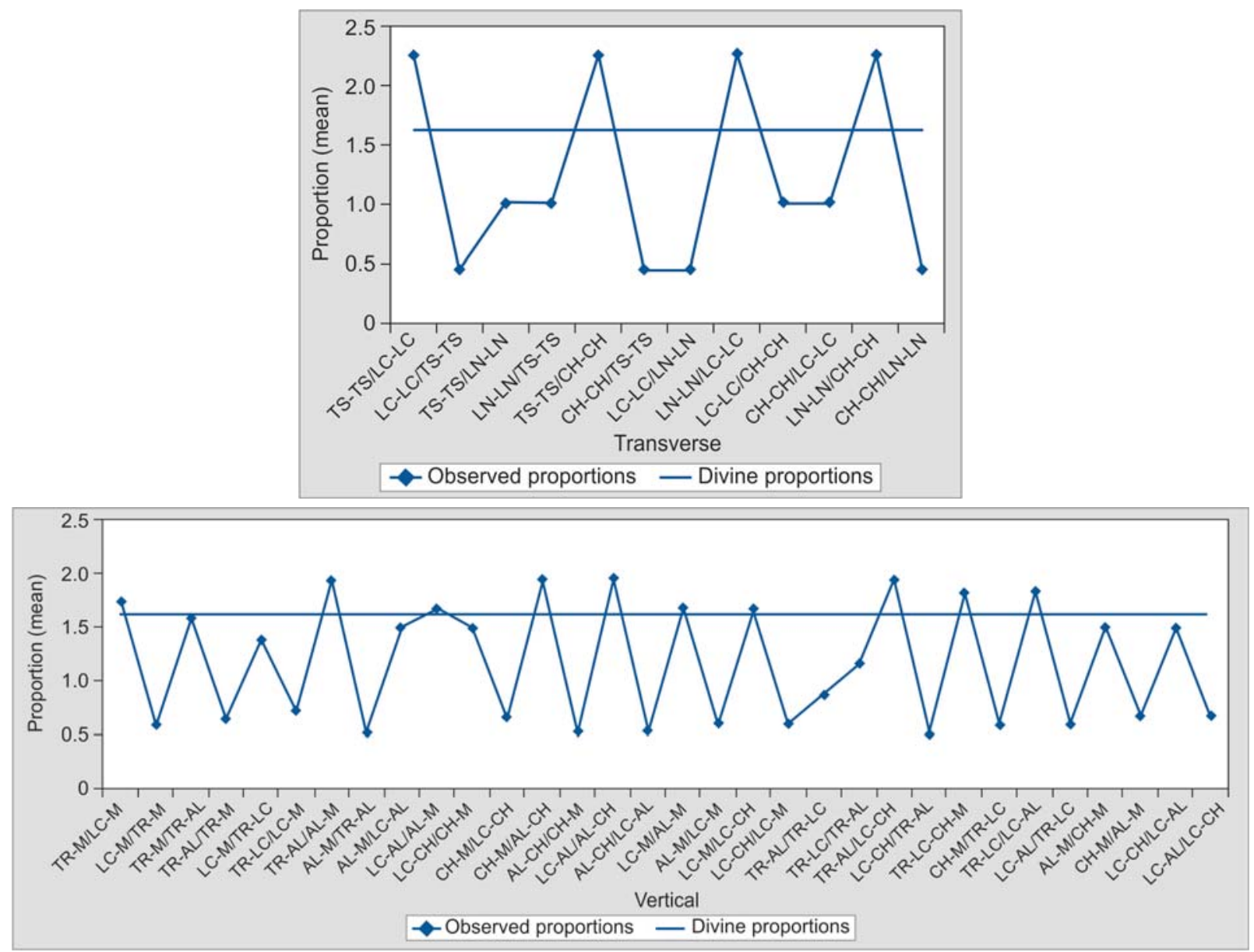

Graph 2: Analysis of proportionality of transverse and vertical measurements

eyes at the lateral canthus), LN-LN:CH-CH (width of nose is golden to width of mouth) is 2.252. Similarly Proffit and White ${ }^{19}$ reported a ratio of the widths of mouth and lower face (2.5), in frontal facial symmetry and concluded that the width of the base of the nose should be approximately the same as the distance between the inner canthi, whereas the width of the mouth should be approximately the distance between the irises.

On photographic vertical analysis it was found that, the facial structures which show golden relation to each other are LC-M:TR-M (lower and mid anterior facial height is golden to total facial height), 0.585; TR-M:TR-AL (upper and midfacial height is golden to total facial height), 1.582; LC-AL:AL-M (midfacial height is golden to lower facial height), 1.677; CH-M:LC-CH (lower one-third of facial height is golden facial height is golden lower one-third of anterior facial height, 0.640; LC-M:LC-CH (upper mid onethird and lower one-third is golden to lower one-third of face), 1.678; CH-M:TR-LC (lower one-third of facial height is golden to upper two-third and mid one-third of face), 0.582; LC-AL:TR-LC (mid one-third of facial height is golden to upper two-third of face), 0.594; CH-M:AL-M (showing lower one-third of face golden to menton), 0.668; where $t \leq 3.65$ was very highly significant.

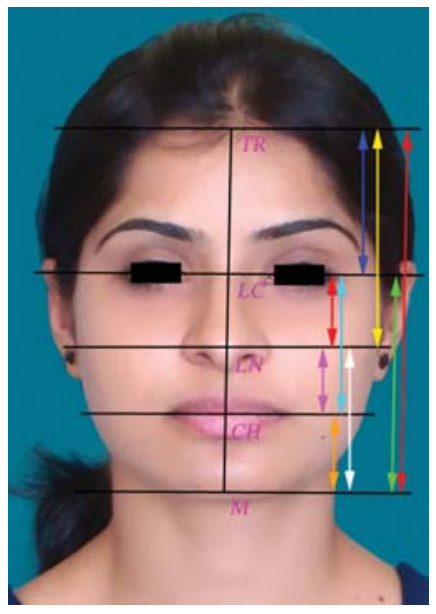

Fig. 5: Landmarks and measurements for facial height analysis

We found that LC-M:TR-M (lower and mid anterior facial height is golden to total facial height) viz (1.7394) is within standard error of 95 to $105 \%$, TR-M:TR-AL (upper and midfacial height is golden to total facial height; 1.582) within standard error 90 to $110 \%$. This was in accordance with the results of Mizumoto et al, ${ }^{18}$ who reported that the TR-M:LC-M was (1.620) within standard error of 97 to $102 \%$ and TR-M:TR-AL was (1.69) with standard error of $104 \%$ with the conclusion that attractive faces has strong statistical tendency toward golden ratio. 
In our study, we found LC-AL:AL-M (midfacial height is golden to lower facial height; 1.677), which was close to divine proportion. Similar results, i.e. (1.600) were found by Mizumoto et al ${ }^{18}$ who concluded that the vertical height of the midface, from the supraorbital ridges to the base of the nose, should equal the height of the lower face, and in the lower face, the mouth should be about one-third of the way between the base of the nose and the chin.

In our study we found 2.80 to $12.08 \%$ (percentage) deviation from ideal values of transverse and vertical reference distances in subjects; whereas Ferring and Pancherz ${ }^{20}$ showed that the average percentage deviation varied between 10.5 and $18.5 \%$ for female subject, indicating that divine proportion is rarely achieved in ordinary people.

Our study considered $\pm 5 \%$ of SEM deviation from divine proportion. Subjects included in the study exhibited closely divine facial proportions. These results are in accordance with those of Heiss ${ }^{21}$ who analyzed the beautiful faces of cover models, the respective deviation were only 2.6 and 4.4 to $5.0 \%$ in women. This shows that attractive faces exhibit greater concordance with the divine proportions than with common faces.

Our study concludes that more beautiful faces show less deviation from golden proportions, with little variance in young attractive North Indian faces.

\section{CONCLUSION}

The present study was conducted to analyze the structural morphology of esthetically attractive faces in North Indian females and to assess the significance to divine proportion using photographs.

Conclusion derived was:

Photographic transverse and vertical facial proportions showed high significance to divine proportion.

This shows that the underlying hard tissue has a significant relationship with facial attractiveness.

However, one must consider the (n) number of various measurements that can be made in an area as anatomically complicated as human skull and further study relative to this mathematical relationship is needed before ascertaining its implication as an important parameter for achieving esthetic harmony.

\section{REFERENCES}

1. Matoula S, Pancherz H. Skeletofacial morphology of attractive and nonattractive faces. Angle Orthod 2006;76:204-10.

2. Ricketts RM. The biologic significance of divine proportion and Fibonacci series. Am J Orthod 1982 May;81(5):351-70.
3. Rudee DA. Proportional profile changes concurrent with orthodontic therapy. Am J Orthod Dentofacial Orthop 1964;50:421-33.

4. Ricketts RM. The golden divider. J Clin Orthod 1981;15:752-59.

5. Muzj E. Musical and architectural proportions in anatomy of facial system: An anthropometric approach. Angle Orthod 1982;52:177-212.

6. Moorrees CFA. Natural head position: A revival. Am J Orthod Dentofacial Orthop 1994;105:512-13.

7. Lines PA. Profilemetrics and facial esthetics. Am J Orthod Dentofacial Orthop 1974;73:648-57.

8. Sushner NI. A photographic study of soft tissue profile in Negro population. Am J Orthod Dentofacial Orthop 1977;72:373-85.

9. Kerr WJS, O'Donnell JM. A panel perception of facial attractiveness. Br J Orthod 1990;17:299-304.

10. Zylinski CG, Nanda RS, Kapila S. Analysis of soft tissue facial profile in white males. Am J Orthod Dentofacial Orthop 1992;101:514-18.

11. Lundstrom A, Cooke MS. Proportional analysis of the facial profile in natural head position in Caucasian and Chinese population. Br J Orthod 1991;18:43-49.

12. Czarnecki ST, Nanda RS, Currier GF. Perceptions of a balanced facial profile. Am J Orthod Dentofacial Orthop 1993;10: $180-87$.

13. Benson PE, Richmond S. A critical appraisal of measurement of the soft tissue outline using photographs and video. Eur J Orthod 1997;19:397-409.

14. Cochrane SM, Cunningham SJ, Hunt NP. Perceptions of facial appearance by orthodontists and the general public. J Clin Orthod 1997;31:164-68.

15. Mantzikos T. Esthetic soft tissue profile preferences among the Japanese population. Am J Orthod Dentofacial Orthop 1998;114:1-7.

16. Faure JC, Rieffe C, Maltha JC. The influence of different facial components on facial aesthetics. E J Orthod 2002;24:1-7.

17. Kiekens RMA, et al. Objective measures as indicators for facial esthetics in white adolescents. Angle Orthod 2006;76:551-56.

18. Mizumoto $\mathrm{Y}$, et al. Assessment of facial golden proportion among young Japanese women. Am J Orthod Dentofacial Orthop 2009; 136:168-74.

19. Proffit WR, Fields HW. Contemporary orthodontics (3rd ed). St. Louis: Mosby 1997;157-63.

20. Ferring V, Pancherz H. Divine proportion in the growing face. Am J Orthod Dentofacial Orthop 2008;134:472-79.

21. Bashour M, et al. An objective system for measuring facial attractiveness. Plast Reconstr Surg 2006;3:757-74.

\section{ABOUT THE AUTHORS}

\section{Anand Awadhesh Tripathi (Corresponding Author)}

Senior Lecturer, Department of Orthodontics, VYWS's Dental College and Hospital, Amravati, Maharashtra, India, e-mail: anand.tripathi86@ gmail.com

\section{Ragni Pradip Tandon}

Professor, Department of Orthodontics, Saraswati Dental College and Hospital, Lucknow, Uttar Pradesh, India

\section{Navin Hantodkar}

Professor and Head, Department of Orthodontics, VYWS's Dental College and Hospital, Amravati, Maharashtra, India 